\title{
The implementation of a shared reading programme within a university: a case study
}

Alison Baverstock, Jackie Steintiz, Laura Bryars, Michael Kerin, Naomi Peel, Rachel Stohler and Elle Waddington, Kingston University

\begin{abstract}
Based on research into the benefits of involvement in reading for pleasure and the operation in the US of pre-arrival shared reading schemes for those about to embark on a university education, both within the context of wider research into how to engage newly arrived students in their institution, an exploration was made of the likely response to such a shared reading scheme within a London university. A representative sample of current first years were asked about their how they spent their leisure time, their attitudes towards and involvement in reading for pleasure and their reactions to such a potential scheme. The findings were that more reading for pleasure was taking part than had been anticipated, that students were generally keen to become more involved in reading and that a shared reading scheme would be welcomed by the majority of students. The decisions made on the basis of the outcomes are discussed, along with recommendations for future associated research.
\end{abstract}

\section{Introduction}

One of the key principles supporting the development and delivery of the Masters course in Publishing at Kingston University has been a strong commitment among the staff to supporting reader development. Applicants for places are informed early that if they come to Kingston they will be encouraged to think about a future as publishers who seek to develop and curate content of interest to a broad range of markets - not just the demograph to which they belong themselves and that part of this is a personal sense of responsibility towards encouraging more people to read. The course has had a strong track record in securing temporary work placements within organisations involved in reader development, and many students have gone on to develop their dissertation or future career within the broader area of widening participation in literacy, both reading and writing. Staff have consistently shared their own commitments in this area (McKearney M. \& Baverstock A. (1990); Baverstock and Gordon, 2011; Watts, 2011 and Baverstock 2013).

The research reported on in this paper relates to investigating the likely receptivity of the target population for a shared reading programme within the community of those coming to a university, and an exploration of both their likely associated interest and potential for involvement. This paper will cover the findings of the research project, and the immediate developments that followed. It is anticipated that further papers will explore the outcomes of the project in more detail. Overall, developments reported are part of a wider practice as research projects in which outcomes are influenced by both the primary research and subsequent practical involvements.

\section{Background}

It was at a conference in the US that the first author of this paper came across the concept of shared reading schemes for students starting at university. At the $2006\left(4^{\text {th }}\right)$ International Conference of the Book in Boston, such schemes were sufficiently well established for papers to be accepted on their component parts and various stages involved, without the need to explain the overall concept. A paper was attended on how to choose a book for such a scheme; the various options available and how different universities operate. 
The paper in question was given by Professor Charles Grenier and considered 'Which one book would you recommend to entering college freshmen?' (Grenier, 2006). At the point at which the presentation was made, Professor Grenier, from Louisiana State University, reported that 'over 95 colleges and universities in the US have developed summer reading programs (SRP) for entering freshmen. At Louisiana State University a committee of faculty members and students from a variety of disciplines review books during the spring term, and one book is chosen for all 5,000 incoming freshmen. Each student is given a free copy of the book at the June orientation session to read during the summer, and in August the book's author addresses the students at a general assembly. Following the lecture, students are divided into small discussion groups guided by volunteer faculty members. The book is used in a variety of ways during the fall term, and this year the SRP has been expanded to include the local citizenry in a program called the One Book One Community initiative.' Professor Grenier's paper presented the results of a survey of all existing university summer reading programs in the U.S. to learn (1) which books have been chosen in the past (2) what the criteria was for the choices made, (3) the selection process, and (4) the organization of each program.

In fact Grenier's paper was one of several at the 2006 conference, within the strand 'Books, Writing and Reading', to explore the impact of shared reading. Others included analysis of the BBC's The Big Read (2003), which sought to find the UK's most-loved novel (Wright, 2006); the impact of Oprah Winfrey's book club on television in promoting shared reading (Farr, 2006); the impact of a university-wide reading program in Dohar, which built on Chicago's whole city reading scheme (Featherston, 2006); the role of books in an after school club for girls (Conley, 2006) and the role of shared reading on women in leadership roles (Knorr, 2006). Although all these papers occurred within the same strand, it is interesting to note their very cross-disciplinary origins. The paper that prompted interest was from a professor from the School of Social Work; Dr Wright was funded by CRESC (ESRC Centre for Research on Socio-Cultural Change within the discipline of Sociology), and other contributions came from Women's Studies and Education - as well as the more predictable field of English.

The first author of this paper mentally stored the idea, thought about how it might be implemented within her own institution and how both support and funding might be found. Eight years later, an opportunity arose, as part of Kingston University London's SADRAS scheme. SADRAS (Student Academic Development Research Associate Scheme) has its origins in a successful proposal to the Higher Education Academy in 2012 to implement a 'Student as Partners' programme, and the scheme established is funded through the Access Working Group. Collaboratively managed by the Kingston University Students Union (KUSU) and the Centre for Higher Education Research and Practice (CHERP), this project is also the first step in a wider effort to build a partnership that ensures that students and staff are equal, engaged partners in an academic community that drives forward learning, teaching, research and innovation.

SADRAS aims to encourage students and staff, in equal partnership, to undertake educational research with the purpose of improving the academic experience of students at the university, particularly those from under-represented groups. It facilitates, in part, the enactment of Kingston's 'Led by Learning' organisational strategy, by enabling Kingston students to actively contribute to course development as part of a learning community. The work encourages collaboration between students and staff, enabling students to both provide a perspective on how the student experience might be improved but also to undertake paid research in an academic environment. 
Both students and staff are invited to submit a project proposal that has a focus covered by the overarching themes of progression, attainment and employability of Kingston University students. It is expected that the majority of successfully funded projects will focus on the achievements, progression and retention of one or more of the following groups of students who have not traditionally thrived at university: black, minority and ethnic students; first generation students, mature students; those who have responsibilities as carers and disabled students.

Having explained the role and significance of reader development within the publishing industry during induction week, the first author of this paper suggested a related SADRAS application to students from across the course who had expressed a particular interest in this area during their first meeting with their personal tutor. She proposed an application for research into the development of a shared reading scheme for first years. Rather than seeking to establish a scheme solely targeting those principally intended to benefit from SADRAS initiatives, it was suggested that the proposal should be set in the context of the organisation as a whole. A project was discussed to breach divides between those coming to Kingston from different backgrounds and walks of life, to enhance a sense of community among new students and to connect Kingston's five faculties, administrative and academic staff, both with students and with each other, but to do this through a scheme likely to appeal to all, without making any group feel particularly targeted or stigmatised.

The opportunity to work with a staff member on such a project attracted the interest of five MA Publishing students. A sixth member joined the group when, as a final year undergraduate who was interested in joining the Masters programme, she was shadowing the lecturer, and hence joined an early meeting of the SADRAS group. Her contribution was so strong that she was invited to join the group. One of the Masters students subsequently withdrew from the group due to ill health.

\section{Literature review}

The benefits of reading for pleasure have been widely documented. For example, Moyer (2007) found that regular readers were also better at understanding other people's class, ethnicity, culture and political perspectives. Sullivan and Brown (2013) investigated links between reading and scores in a variety of other academic tests, finding a positive correlation, particularly in the case of the development of vocabulary. Positive links were also found between involvement in reading within adults with specific additional needs such as low literacy levels, disadvantageous background or incarceration and have shown positive correlations between reading and the acquisition of transferrable skills (Prison Reading Group, 2010). Billington (2015) reported that reading for pleasure correlates with a greater sense of community, stronger feelings of social inclusion, and a greater ability to enjoy social occasions.' Most recently, research by BOP Consulting commissioned by The Reading Agency (2015) reviewed the relevant literature and identified specific benefits experienced by those regularly reading for pleasure. For the general adult population these included 'enjoyment, relaxation and escapism, increasing understanding of self and social identities, empathy, knowledge of other cultures, relatedness, community cohesion and increasing social capital' ( $p .5$ ) with 'a relatively substantial amount of research relating links between recreational reading and health' among adults with health needs (p.10) and 'findings related to communication, self-efficacy, learning motivation and relatedness' for adults with additional needs, where studies had 'tended to focus on adults with below average levels of literacy.' (p.10). 
Shared reading within book clubs has been studied, most notably by Jenny Hartley in the UK and Elizabeth Long in the US (e.g. 2003). Hartley's extensive study (2001) of primarily UK reading groups identifies the search for knowledge and the desire to belong/contribute to a community as two key motivations for membership. Sedo (2003) quotes Elizabeth Long's 1992 essay 'Textual Interpretation as Collective Action' and cites Long (1992) as 'successfully arguing that an individual's participation in a book club is based on a shared need that informs the individual's sense of identity and contributes to the group's solidarity. Reading is thus transactional not only between reader and text but also between reader, text and group.' Barstow (2003) concluded that such groups fulfil 'the need for some level of bonding. Book clubs, as we have seen above, provide the opportunity for such bonding...' Cregan (1993) explored the role reading groups are playing in bridging academic and popular culture and in the UK DCMS (2013-14) explored their extent and participation levels.

The operation of shared reading has of course also been very influenced by related developments within the media, notably Oprah Winfrey in the US and Richard and Judy in the UK, both of whom ran book clubs as part of magazine programmes on day time television. Hall (2003) begins his study of the 'Oprahfication' of literature by looking at reading groups in general, and their wider - and historical - role in culture. He talks of reading groups in a historical sense, prominent in middle class American life from the mid-1800s onwards - and then outlines the contribution made by such discussions being hosted on television. He highlights in particular the sense of community created through the intimacy of sharing reactions to, and personal thoughts around, the book and through which 'an illusion of intimacy establishes a moral bond between Winfrey and her viewers, a bond Steven Shapin (1994) calls 'trust'. This trust is crucial to Winfrey's success as a literary sponsor.' Considering the choice of books made on the Oprah programme, Ted Striphas (2003) highlights the significance that 'the content of specific books was perceived to be valuable by Winfrey and viewer/readers to the extent that it shared a clear connection with life, or that it resonated with their everyday interests, personal experiences, and concerns.' Bartlett (2003) has commented on the extent to which Ophah's influence has penetrated the way books are discussed within university literature programs.

Looking at life post Ophrah (after her 2002 announcement that she would no longer be hosting her monthly book club), Sedo (2002) considers the disparate people brought together through shared reading: 'Other than their love of reading, education levels are the only constant similarity among book club members. They teach, consult, nurse, paint or build computer systems for a living. Their incomes range from $\$ 12,000$ CDN per year to 'plenty', according to another respondent. Some rent, some own. Some are married with children and grandchildren, others are single and some are single parents.' In other words, the habit of sharing books has drawn together a wide variety of individuals.

\section{Research within the student community}

Relevant research on the benefits of reading for pleasure within the student community has been related to both studying students as a specific - and presumably relatively easily accessible demograph, as well as some work analysing the operation and benefits of pre-arrival shared reading schemes for freshers.

Looking at students as a demograph, Mar et al (2006) found a strong link between reading and social abilities, and in particular that involvement in reading was a predictor of empathy within 
undergraduate students in Canada. Vasquez (2005) concluded that reading enhances students' abilities to understand both their own, and other people's, cultural and ethnic identities.

Shared reading schemes within universities have been found to operate on similar principles. Mostly integrated into new student orientations, Ferguson (2006) confirms that 'campus reading programs rest on a simple idea: that reading the same book brings people closer together as a community by creating common ground for discussion' and Levine Laufgraben (2006) thought that such experiences give students an early taste of academic life and set the tone for the first year of college.

Ferguson (2006) and Golden (2012) both discuss the role such schemes can play in widening participation and promoting engagement - both real issues for universities today. Such developments can also combat the culture of disengagement among students. In No Logo (Klein, 2000) describes how students 'slip into class slurping grande lattes, chat in the back and slip out. They're cruising, shopping, disengaged.' This might also extend to reporting back on their involvement in shared reading. A report by Twiton (2006), as part of a Patricia Lindell Scholarship Research project drew just 130 responses from a student intake of around $2,500^{1}(.05 \%)$; success may be however gleaned from the qualitative comments of those who did provide feedback; numbers attending related events and anecdotal feedback from those involved. It was also anticipated that taking part in pre-arrival shared reading would tend to confirm students' decision to enrol and turn up. In the absence of more data the authors concluded that 'Oprah may contribute to a better understanding of college reading-in-common programs.' Much of the reporting back on the outcomes of pre arrival shared reading within universities is however general and promotional information rather than analytical (see the list of websites within references).

\section{Student engagement}

Moving into the literature on the issue of engagement within the student body, the work of Astin (1984) was particularly significant in seeking to clarify what is meant by the 'involvement' of students; which he identifies as 'refers to the amount of physical and psychological energy that the student devotes to the academic experience.' Considering how to develop such engagement, Astin places significance on student involvement and in particular collaborative learning (student/student and staff/student). Thus both shared reading and SADRAS would count as the kind of endeavour likely to promote engagement and reduce dropping out.

Ashwin (1985) explored the benefits of social engagement in reducing isolation; Sims (2007) and Tienda (2013) concentrated on diversity, 'focusing on inclusion, namely, organisational strategies and practices that promote meaningful social and academic interactions among students who differ in their experiences, views and traits.' Tinto $(1975 ; 1993)$ explored student retention as being predicated on social and academic integration, using social anthropological studies of rites of passage as well as Durkheim's work on suicide to draw parallels between voluntary withdrawals from local communities. Kuh (2008) identified interactive educational practices as offering the best outcomes for retention and attainment. Rodgers (2002) explored the benefits of trying to improve attendance at tutorials and found it did not improve academic performance, concluding that

\footnotetext{
${ }^{1}$ http://colleges.usnews.rankingsandreviews.com/best-colleges/gustavus-college-2353 'It has a total undergraduate enrollment of 2,456,'
} 
'Physical presence and intellectual involvement are quite different phenomena' and that 'More information is needed on why students skip classes and how they utilise the time so gained.' Baron and Corbin (2012) observed "universities are "cascading" down the need to improve student engagement to schools and ultimately to individual academics' and that the reengagement of students 'cannot be successful until a "whole-of-university" approach is adopted'. Writing in the Times Higher Education Supplement, Gibbs (2014) considers engagement as a buzzword, and considers rather how it can help promote learning.

Of particular importance to the current study, Astin also outlined the significance of student accommodation to their successful adaptation to higher education, 'living on campus substantially increases the student's chances of persisting and of aspiring to a graduate or professional degree.' Along similar lines, in her exploration of Student Experiences of Diversity in UK Universities (2007), one of Mai Sims key findings was that 'BME students accepted to a first degree course were more likely to travel less distance on average to university than White students, a greater proportion opting to live at home.' Within the report, she also commented that: 'Numerous studies have shown that interaction with close friends of a different race or ethnicity is a powerful way in which students accrue the educational benefits of enhanced self-confidence, motivation, intellectual and civic development, educational aspirations, cultural awareness and commitment to racial equality, from a racially diverse student body.'

\section{Methodology}

It was tempting to use this research as a basis on which to establish a shared reading project straight away, and observe its impact. But as SADRAS is a research scheme, it was decided to use the resources available to gauge potential interest in a shared reading scheme for first years by interviewing the current cohort.

A survey was developed using SurveyMonkey. The group agreed that the target population for the research would be first year students, and a sample population was constructed by asking the KU data department to provide email access to the five largest undergraduate cohorts, one per faculty. These courses were Psychology (Faculty of Arts and Social Sciences), Adult Nursing (Faculty of Health, Social Care and Education), Architecture (Faculty of Art, Design and Architecture), Business Management (Faculty of Business and Law) and Biomedical Science (Faculty of Science, Engineering and Computing).

An online questionnaire was developed using SurveyMonkey, and extensively reviewed by all in the group. It was entitled 'Leisure Survey' as it sought to establish current levels of reading for pleasure, and attitudes towards it, within the wider context of how respondents used their free time. The question format was a mix of multiple choices, rating scales with a 7 point scale ( 1 is low, 7 high, 4 the mid-point), and open-ended questions, as these are particularly useful in providing insights.

The questionnaire was divided into three stages: firstly asking recipients about their leisure habits; secondly their attitudes to reading and their reading habits; finally moving on to describing how a shared reading scheme might work in practice and asking if they might have been interested in taking part, had this been available to them. 
Once the approach and the questionnaire itself had been approved by Kingston's Ethics Committee, contact was made with the first year tutors, administrative staff and learning support team in these disciplines to encourage participation in the survey. The questionnaire was tested on the MA Publishing cohort to ensure clarity and ease of response and then rolled out to first year students of the five undergraduate cohorts outlined above from the end of January 2015.

The cohort was emailed four times, each time with a covering email written by one of the students, and from the generic email address 'Leisuresurvey@kingston.ac.uk' rather than that of an individual. As named responses were not kept, in follow up emails those who had previously replied were asked to ignore the link. It was only possible to reply to the survey once.

Interviews were set up between student representatives of the group and both the Vice Chancellor and Baroness Gail Rebuck, former Chief Executive of Random House who has been prominent in promoting reading. Baroness Rebuck founded Quick Reads - attractively presented titles with limited vocabulary for unconfident adult readers. She pronounced herself to be very impressed by the scheme and offered the following endorsement: 'Your aim is to engage the Kingston community through shared imagination into a shared world.'

\section{Findings}

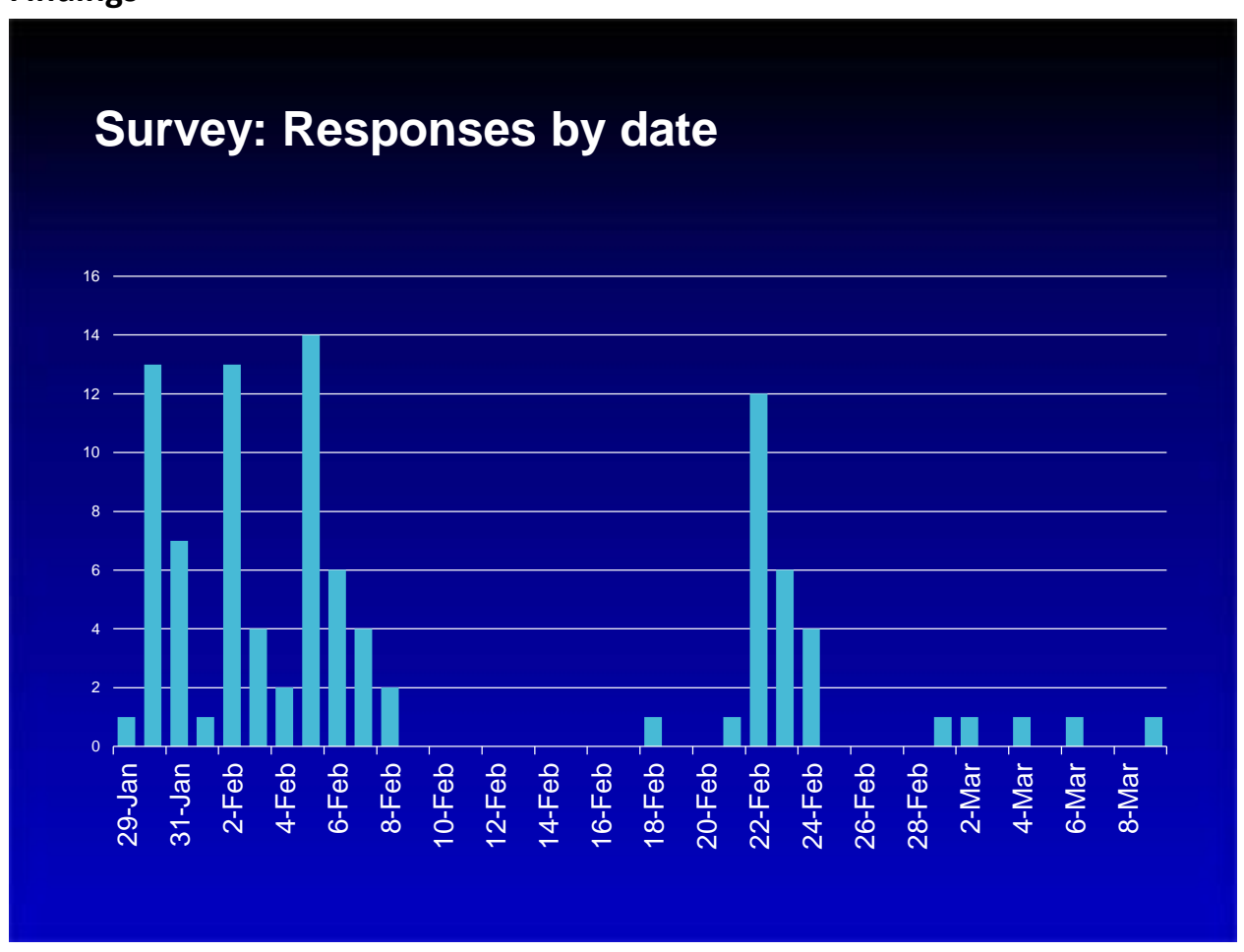

The basic finding from despatch was that when mailed a link to the questionnaire, recipients either responded within a couple of days - or did not; reminding them had the same effect. Overall, 800 students were contacted and 97 replies were received, across the board of subjects - a response rate of about $12 \%$. The population of responders was somewhat skewed towards women and more ethnically diverse than the population of the university as a whole. There were most responders from Adult Nursing, least from Architecture. 59\% took a break from study before the course. Of the respondent, only $20 \%$ lived in halls of residence and $35 \%$ were first generation students. 
It was frustrating to find that there was a gap in the middle of the project when no questionnairing was possible. This was due to official KU surveys going out, and in particular the National Student Survey, but information on this serious interruption to the planned schedule had not been available beforehand. Had this been known about beforehand, questionnairing could have started earlier.

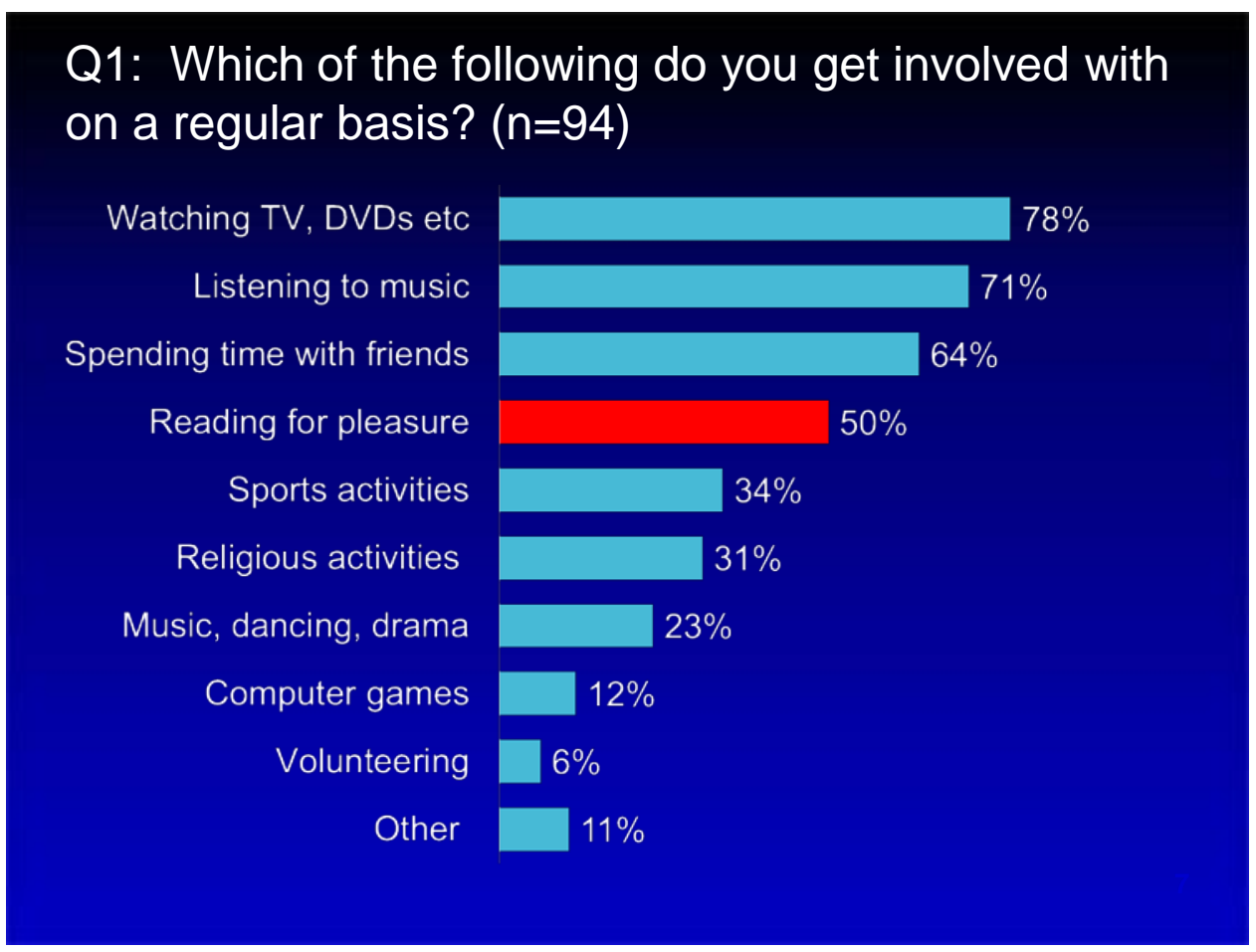

The survey began by asking respondents about how they spent their leisure time. A list of options was provided with a final choice of 'other'. Reading for pleasure emerged high up the list with $50 \%$ of those responding saying they were involved on a regular basis.

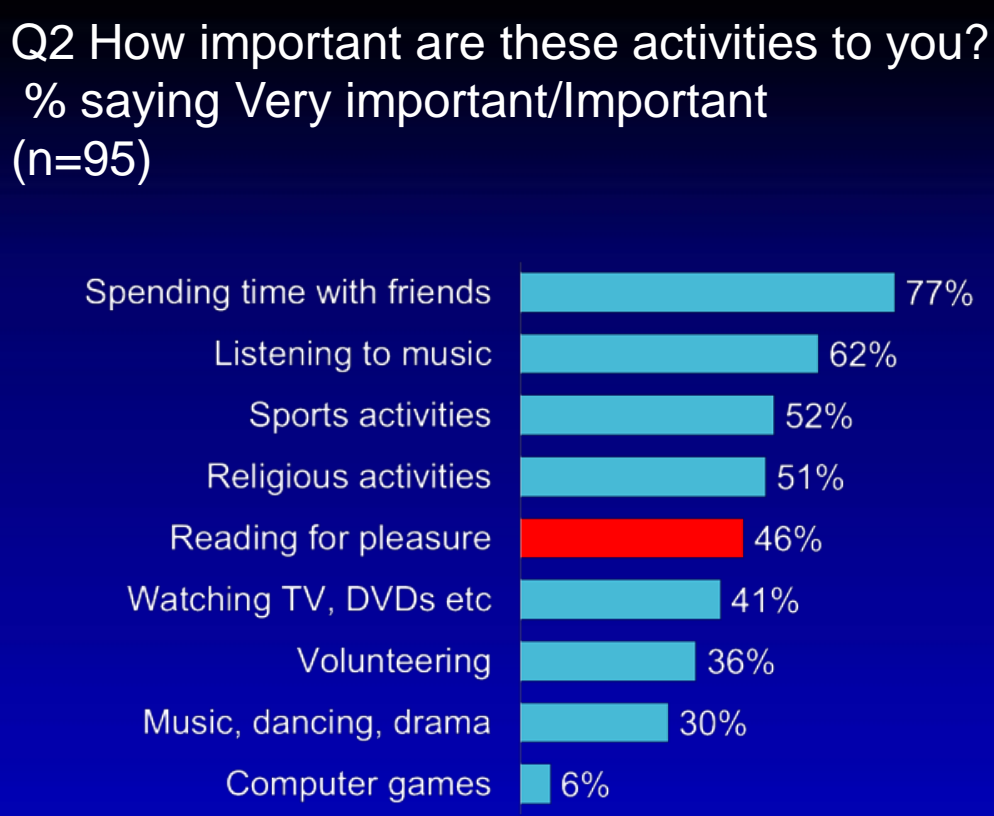


Recipients were then asked to rate the respective importance of these activities, and it is significant that 'Reading for pleasure' held its place, with $46 \%$ saying it was 'important' or 'very important'. By contrast, 'Watching television, DVDs etc' moves from $78 \%$ cohort involvement 'on a regular basis' to $41 \%$ when asked how 'important' or 'very important'.

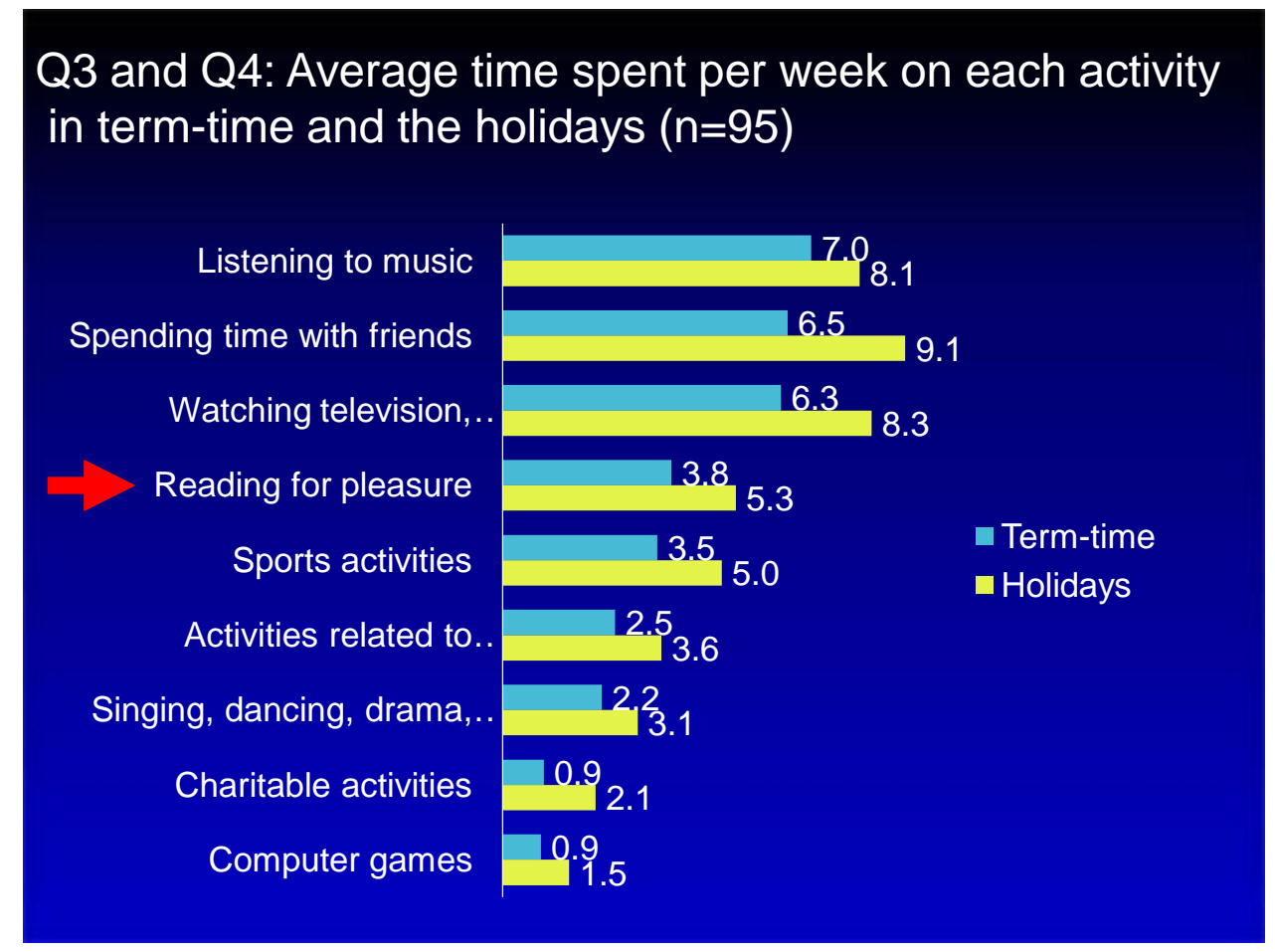

Recipients were then asked to compare how they spent their time, during the term times and the holidays. It was interesting that the differentials between term-time and holidays were less significant for 'Reading for pleasure' (72\%) than some activities such as 'Sports activites' $(70 \%)$ and 'Charitable activities' (42\%) where significantly more time is spent on these activities during the holidays. It can be deduced that reading, listening to music and seeing their friends are activities the students tend to do anyway, whether term-time or not. Another point worth drawing out is that small amount of time apparently allocated to playing computer games, which given their popularity within the student generation may seem unlikely. This may potentially show responder-bias, or perhaps is a function of those who responded to the questionnaire. 


\section{Q5. What kind of material do you read for pleasure on a regular basis?}

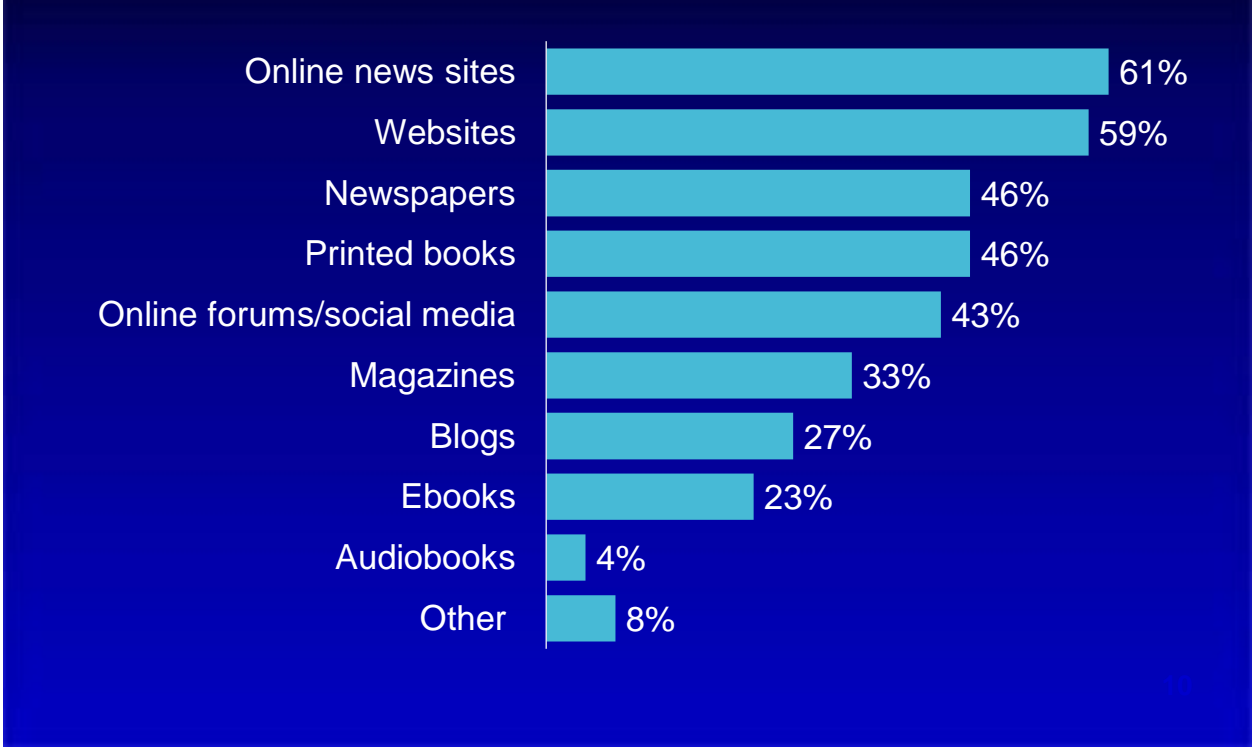

The second section of the questionnaire introduced the idea of asking about their involvement in reading for pleasure. The instruction, beginning a new page, read:

'These questions seek to find out more about your access to reading material. We would like to find out how much time you spend reading for pleasure, what kind of material you enjoy and how you find things to read.'

Asked about the format of material they read for pleasure, by asking respondents to tick all the options that applied to them, it emerged that reading for pleasure is an activity that takes place both on- and off-line and is not limited to printed materials. The decision to divide online news sites from websites was a late one, based on observing student behaviour. This proved to be a significant question, attracting the two biggest categories of reading. 


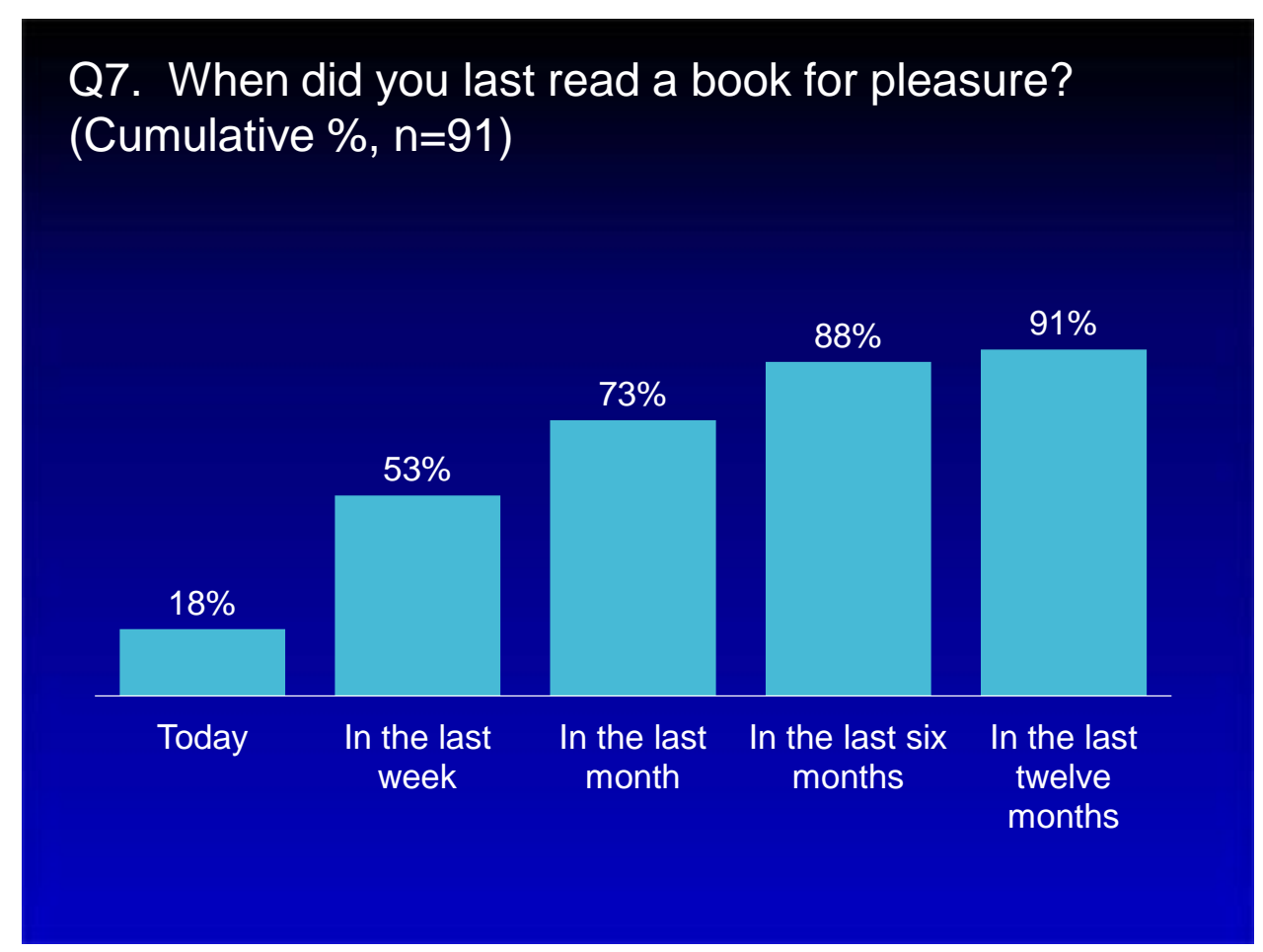

Asking students when they had last read a book for pleasure was particularly revealing. Almost everyone had read a book for pleasure in the last year, and nearly a fifth had to done so on the day of the survey. Reading for pleasure is perhaps more common than perhaps might be assumed from the repeated coverage of its general decline in the press.

Having established when students had last read a book for pleasure, they were then asked to comment on the type of book read (both genre and format) and the experience of reading, in relation to the particular title read. Novels stood out as the most common (52\%) with 'How to/Information titles' (21\%) and 'Non-fiction' (18\%) well behind. Travel (0\%) and other (7\%) were also low scorers. $76 \%$ of the cohort had read a title in print, $23 \%$ as an ebook and $1 \%$ in audio format.

The numbers of those who had discussed the book with someone else were surprisingly high. $63 \%$ of respondents had discussed the book with a friend, $17 \%$ with a housemate, $17 \%$ with a parent, $24 \%$ with another relative, and $4 \%$ with a stranger. And of the experience of discussing the book with someone else, $\mathbf{7 2} \%$ had found the experience somewhat or more enjoyable. Asked whether anyone had noticed or commented on what they were reading, 43\% said yes (and 57\% no). Given that reading is often viewed as a solitary activity, the number who had discussed the book was higher than expected.

The source of the book they had read was interesting. The majority had read a bought title - either purchased online or from a bookshop or received as a gift. $11 \%$ of responders had borrowed the title from a family member or friend. This was an interesting comparison with the MA Publishing students where around $50 \%$ of a much smaller cohort had borrowed from friends, leading to the interesting conclusion that potential publishers may buy fewer of the titles they read than the wider student population (although they read significantly more). 


\section{Q15: How important was reading for pleasure for}

you when you were aged....?

(Four point scale, $\mathrm{n}=84$ )

\begin{tabular}{|c|c|c|}
\hline & $\begin{array}{l}\text { Very Important/ } \\
\text { Important }\end{array}$ & Not Important \\
\hline Under 11 & 52 & 13 \\
\hline $12-16$ & 61 & 7 \\
\hline $17+$ & 66 & 7 \\
\hline
\end{tabular}

A question was asked about their reading habits as younger people, asking them to reflect on their previous involvement in reading for pleasure at three periods of their lives: under 11; 12-16 and 17+. While this was not scientifically tested, and relied on recall, the information gained builds a picture of reading for pleasure being a habit already engrained in responders. As they grew up, the reading habit in responders became more important and the number regarding it as not important went down.

\section{Q16 and Q17: How likely are you to read during} these times?

\begin{tabular}{|l|r|r|}
\hline & Term-time & Holidays \\
\hline Before you go to bed & 41 & 45 \\
\hline Weekends & 38 & 45 \\
\hline Weekdays & 34 & 49 \\
\hline Using public & 33 & 29 \\
transport & & \\
\hline
\end{tabular}

Q19 Did you read for pleasure during Freshers' Week/Induction Week $(n=83)$

Yes 30\%

No $47 \%$

Can't remember 12\%/ Did not attend 11\% 
Asked about when and where they read, all responders reported that they did more reading during the holidays, apart from reading on public transport, where the habit is greater during term time. It should be noted that this is consistent with the student demographics of Kingston University where a lot of students live at home and use public transport to commute, many with an average journey time of over an hour.

Asked about whether they had read for pleasure during Freshers' Week it was surprising to find that $30 \%$ said yes. The assumptions of the research group had been that this week, being consciously packed with organised fun and activities designed to provide a taste of the student experience would leave little time for reading for pleasure. In fact $30 \%$ said they had read for pleasure during this time, and as the option to say they did not attend was a separate one, and students could choose only one option, significant numbers of students may have been reading during this time. While the response may have been subject to responder bias, perhaps seeking to present a positive image to those doing the questionnairing, it leaves an interesting suggestion that more time was spent on solitary activity during this period than might have been previously assumed.

While at Kingston University the research project coincided with a complete reworking of Welcome Week, to place less emphasis on alcohol (which would in turn make the outcomes of the eventual project harder to read) in general the allocation of time to solitary activity fits with the demograph of the Kingston student population, where there are many students who don't drink alcohol for religious, cultural or life-stage reasons (e.g. mature students with families).

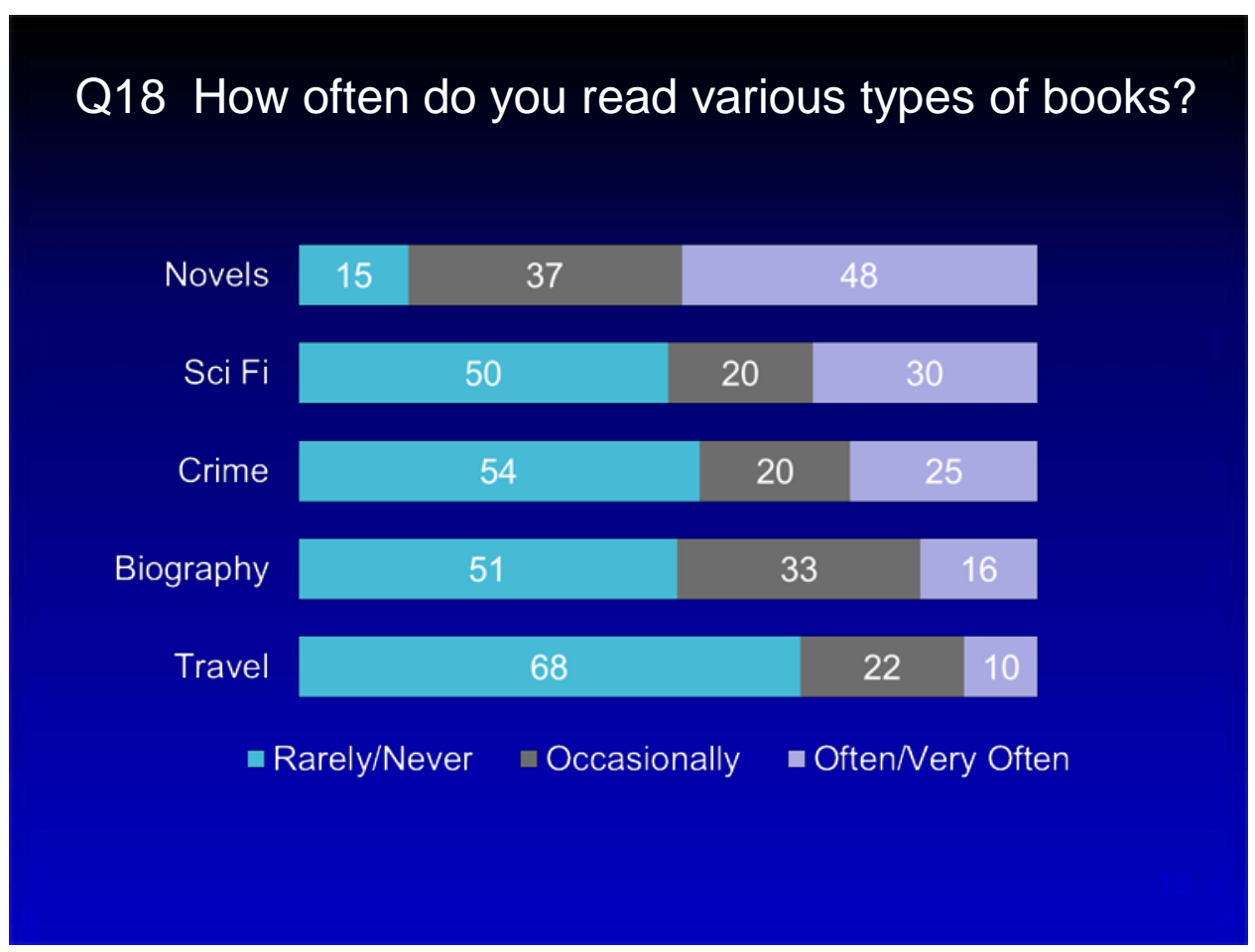

Asked about the kind of titles read for pleasure, the responses showed that certain genres attracted more than others and this is consistent with findings earlier in the research, when asked to specify their most recent reading experience in question 14 . When it came to thinking about reading choices that would unite respondents and finding a book that could be read by the entire population it 
would seem that a novel is least offensive choice - as only $15 \%$ only rarely or never read this format. But $68 \%$ never or rarely read travel and never/rarely read $54 \%$ Science Fiction.

Interesting discussions arose around the separation of categories which had been chosen by the research group. When discussing outcomes to the questionnaire in seminars with academics, there were occasional comments that Sci Fi was surely part of novels; whereas they were viewed as separate categories by the Publishing students who had drawn up the questionnaire.

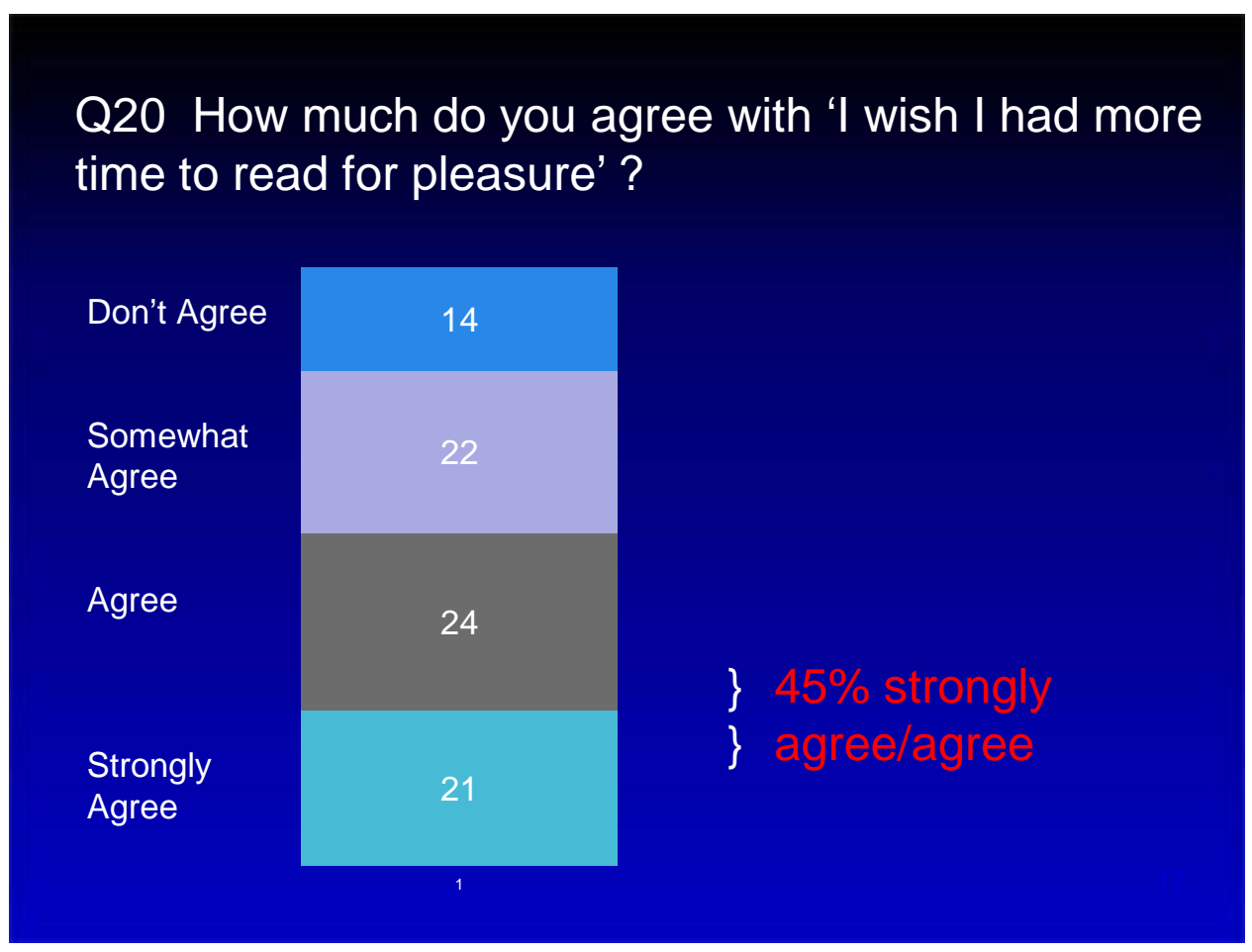

Asked about how much time they were able to allocate to reading, a strong percentage of respondents agreed that they would like to have more time to read for pleasure, with $67 \%$ saying they agreed with the statement 'I wish I had more time to read for pleasure' and only $14 \%$ disagreeing. 


\section{Q21 If you do not read for pleasure what are things that stop you?}

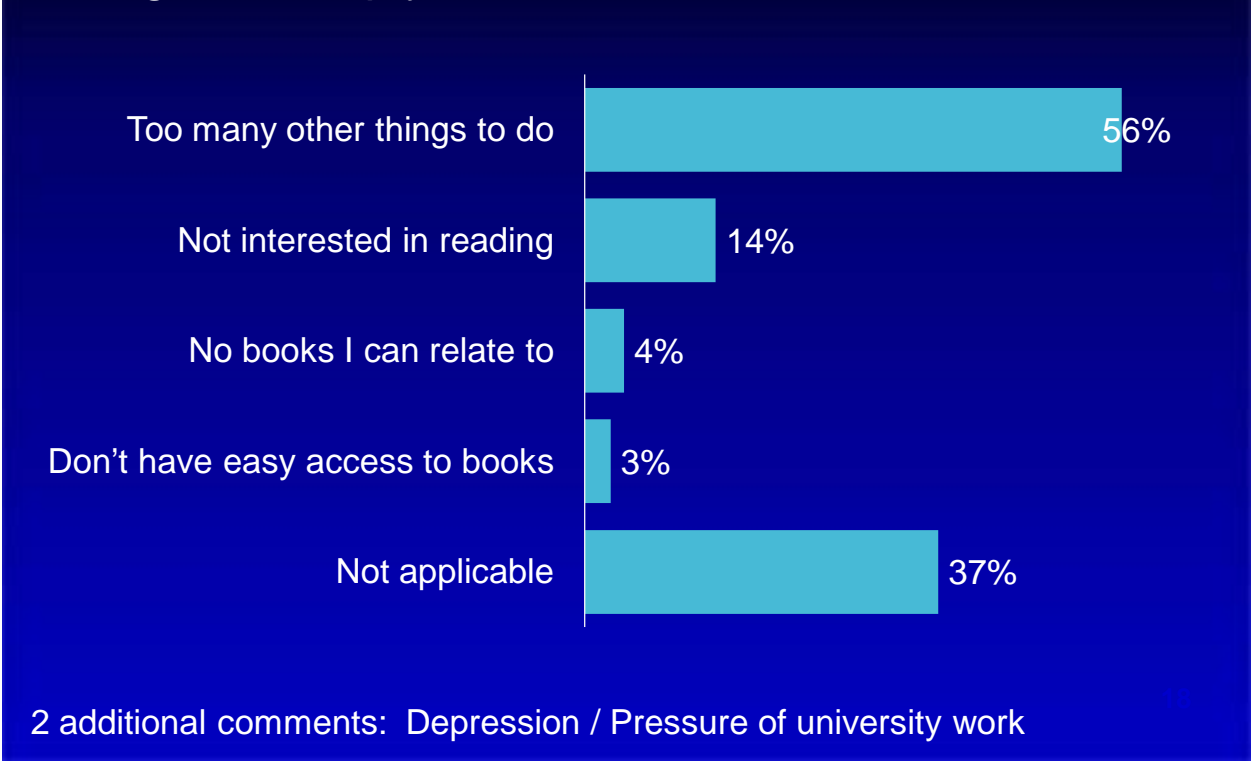

Asked about what stopped further involvement in reading for pleasure, there was a consistent answer of 'too many other things to do' (56\%). Some of the other smaller categories ('not interested in reading'; 'no easy access to books'; 'no books I can relate to') all offer challenges to providing information on relevant titles. 'Not applicable' in this context means those who are already reading, so the question was not appropriate.

The questionnaire then began a third section of questions asking about potential responses to a shared reading scheme among those embarking on university life. The section was introduced as follows:

'We hope that the information provided through this survey will help us consider the feasibility of setting up a university-wide reading scheme. This would offer all new students a free book and encourage them to read it before they arrived at university. During the first few weeks of term there would be an opportunity to talk about the book with other staff and students.'

Asked if they thought this an interesting idea, 31\% thought it 'somewhat' and 46\% 'very interesting' with only $5 \%$ saying it was 'not interesting'. If the scheme had been operating when they arrived at university, $58 \%$ would have taken part, with $34 \%$ unsure - and $8 \%$ said no $(n=83)$. Thus if those responding 'unsure' are counted as maybes, there was a potential $92 \%$ of respondents potentially interested in taking part.

When the response to whether or not those surveyed would have taken part was analysed by accommodation type, an interesting pattern emerged.

By accommodation type, the responses to 'Would you have taken part' broke down as follows: 


$\begin{array}{ll}\text { Private student hall of residence } & 86 \% \\ \text { Shared accommodation (e.g. a flat) } & 71 \% \\ \text { Your family home } & 65 \% \\ \text { Student hall of residence } & 19 \%\end{array}$

Those living in official university accommodation, presumably with a ready source of company and distraction, were least likely to want to take part. This response is also a good match for the student cohort at Kingston, where a significant number live in their own homes or lodgings due to their particular circumstances/beliefs - and in particular for the communities that SADRAS seeks to reach. Shared reading could offer a way to connect at university that is particularly valued by those not living in university accommodation or halls of residence. This confirms related research by Astin (2007) and Sims (2007) outlined in the literature review above.

\section{Barriers and benefits to implementing a shared reading programme}

This paper sought to establish the feasibility of establishing and delivering a shared reading programme within a university. When asked directly about the barriers that might dissuade students from taking part, there were 53 qualitative comments, most of which centred on 'lack of time' ('being too busy'; 'too many assignments'; 'too much other reading'). Other responses centred on the personality characteristics of individual students ('lack of confidence' about taking part; general 'laziness') or the title chosen being either interesting, or necessarily related to the course selected before the students would get involved. There were a few references to books being 'boring'/the lack of a desire to read and one respondent thought a book sharing scheme something more likely to appeal to children.

When asked about the potential benefits of such a scheme however, it was noticeable that respondents' language changed, and they began to use terms relating to employability. Respondents referred to the importance of 'networking and connections' ('meeting people'; 'having a sense of community'; 'inclusion even before arriving'); to the project offering 'potential for confidence building' (e.g. 'practice in speaking up'; 'knowledge of grammar'; 'development of thinking skills'; 'help with essay writing and exam preparation'). The scheme was isolated as beneficial for particular learning needs (e.g. 'students who need to improve their English', 'who do mostly practical work' or 'who have not read for a while'). It was also perceived as offering useful 'time out' from the standard curriculum and general encouragement for reading, which was seen as a positive. Overall the vocabulary used in responses to this section differed from that used in the barriers section; with consistent use of the language of CV preparation there was evidence that students appreciated how the scheme could make them more employable.

\section{Conclusions}

The conclusions gained from this research supported the idea that more involvement in reading for pleasure would be a benefit to the KU student population, particularly as an aid to transition into a student within higher education. It can be concluded that:

1. Reading for pleasure was identified as important to a significant proportion of first year students.

2. Encouraging more reading for pleasure was seen as likely to reignite a former reading habit rather than requiring a start from scratch. 
3. There was strong evidence of support for the proposed scheme across most demographics.

4. The scheme would be of particular value to those not living in halls of residence.

5. Particular attention needs to be paid to the timing when seeking to questionnaire students for research projects, and any self-imposed limitations.

6. Given this level of support across all demographics, and the positive responses to those planning to come to $\mathrm{KU}$, the scheme could double as a very cost effective form of marketing for the university.

\section{Longer term development of this research}

The outcomes of the project were presented at a SADRAS conference at which posters were displayed of all projects and the findings reviewed. The opportunity for them to be observed by students, academics and the university senior management officially marked the end of the project, and the end point at which student involvement was paid.

This particular project was highlighted in the VC's review of the submissions - and he expressed the hope that it would now be put into action. The SADRAS management team have been concerned that the projects should be sustainable rather than simply noted, and there was encouragement to take the outcomes forward and establish a shared reading scheme for Kingston University with progress being made immediately. The students who had taken part were offered the option of continuing to implement the project, rather than wait for others to do this on their behalf. All chose to remain involved; not only were they personally committed, they found involvement in the project a consistent aid to their employability.

A decision to move ahead immediately however placed pressure on the team to choose a bookthere being insufficient time to develop a research process to think about how a title might be selected. At this point Kingston's VC, suggested the title About a Boy be chosen by Nick Hornby - it's about transition and growing up, and set in London. Nick Hornby is also a Kingston alumnus. During the remainder of the summer the SADRAS team worked on, organising a print run of the books with a Kingston logo on it, arranging for the $\mathrm{VC}$ to write a foreword and writing questions to prompt discussion to go in the back of the book. This activity, as well as determined efforts to monitor the project's impact on enrolment, progression and engagement, will be reported in a subsequent paper.

\section{References:}

Ashwin, P. (2006) 'Interpreting the developments: possible futures for learning and teaching in higher education' in Ashwin. P. (ed.) Changing higher education: the development of learning and teaching, London: Routledge, pp. 127-134.

Astin, A. (1984) 'Student involvement: a development theory for higher education', Journal of College Student Personnel, 40 (5) pp.298-307.

Baron, P. and Corbin, L. (2012) 'Student engagement: rhetoric and reality', Higher Education Research and Development, 31:6: pp.759-772.

Barstow, J.M. (2003) 'Reading in Groups: Women's Clubs and College Literature Classes.' Publishing Research Quarterly (Winter 2003): 3-17.

Bartlett, Thomas. 'Honors Curriculum at UMass Features Oprah-Like Book Club.' The Chronicle of Higher Education 49.25 (28 Feb. 2003): A10. 
Baverstock, A. (2013) 'Reading Force: practice as research in the context of a shared reading project for Forces families', Logos Volume: 24(2), pp.24-32.

Baverstock, A. and Gordon, H. (2013) 'Reading Force: can an experience of shared reading be used as a conduit to effective communication within both services families and their wider communities.' Children in War: The International Journal of Evacuee and War Child Studies, 1(10), pp.77-88.

Billington, J, (2015). Reading between the Lines: the Benefits of Reading for Pleasure, Quick Reads, University of Liverpool.

Conley, K. (2006) Department of Secondary Education, University of Vermont, Burlington, USA. 'A different kind of club: literacies of an after school book club for adolescent girls'. International Conference of the Book, Boston, US.

Cregan, Mary. 'Reading Groups Are Bridging Academic and Popular Culture.' Chronicle of Higher Education (19 December 1997): B4-5.

DCMS (2013-14), Taking part: The national survey of Culture, Leisure and Sport. London: DCMS. Grenier, C. (2006) School of Social Work, Louisiana State University, USA. 'Which one book would you recommend to entering college freshmen?', International Conference of the Book, Boston, US Farr, C.K (2006), English and Women's Studies, College of Saint Catherine, St. Paul, USA. 'Oprah's reading revolution'. International Conference of the Book, Boston, US.

Ferguson, M. (2006) 'Creating Common Ground: Common Reading and the First Year of College'. Peer Review: The Association of American Universities and Colleges, Vol. 8, No. 3, pp8-10.

Fetherston, R.L. (2006) Virginia Commonwealth University School of the Arts in Qatar, Doha, Qatar. 'Books and Reading as Elements of Pleasure: The Meaning of a University-Wide Reading Program in an Oral Society in the Middle East. International Conference of the Book, Boston, US. Gibbs, G. (May, 2014) 'Looking beyond the buzzword', Times Higher Education Supplement. Knorr, H. (2006) University of Minnesota, Pittsburgh, USA. The role of books as mentors for women in leadership positions. International Conference of the Book, Boston, US.

Golden, S. (2012), 'Common Reading, Common Ground' Inside Higher Education.

Hall, R. M. (2003) 'The 'Oprahfication' of Literacy: Reading 'Oprah's Book Club'. College English 65, no. 6 (July 2003): 646-667.

Hartley, J. (2001) Reading groups. Oxford: OUP.

Klein, N. (2000). No Logo. London: Harper Collins.

Kuh, G. (2008) High impact educational practices: what they are, who has access to them, and why they matter. Washington: AACU.

Laufgraben, J.L. (2006) 'Common Reading Programs: Going Beyond the Book' (Monograph No. 44). Columbia, SC: University of South Carolina, National Resource Center for the First-Year Experience and Students in Transition.

Long, E. (1992) 'Textual interpretation as collective action' The Ethnography of Reading, ed. Jonathan Boyarin: The University of California Press, 1992, pp181-212.

Long, E. (2003) Book Clubs: Women and the Uses of Reading in Everyday Life. Chicago: University of Chicago Press.

Mar, R.A. et al (2006). 'Self-liking and self-compteence separate self-evaluation from self-deception: Associations with personality, ability and achievement.' Journal of Personality, 74(4), pp1047-1078.

McKearney M. \& Baverstock A. (1990) Well worth reading: an experiment in fiction promotion. Winchester: Southern Arts.

Moyer, J. E. (2007). Learning from leisure reading. Reference \& User Services Quarterly, 46(4), 66-79. Prison Reading Group (2013) 'What Books Can Do Behind Bars: Report on the work of the PRG 19992013'. 
The Reading Agency and BOP Consulting (2015). 'Literature Review: the impact of reading for pleasure and empowerment.' Available at:

http://readingagency.org.uk/news/The\%20Impact\%20of\%20Reading\%20for\%20Pleasure\%20and\%2 OEmpowerment.pdf (Accessed $9^{\text {th }}$ October 2015).

Rodgers, J. (2002) 'Encouraging tutorial attendance at university did not improve performance', Australian Economic Papers , 41 (3), pp.255-266.

Sedo, D-N. R. (2002) 'Predictions of Life After Oprah: A Glimpse at the Power of Book Club Readers.'Publishing Research Quarterly (Fall 2002): 11-22.

Sedo, D-N. R. (2003). 'Readers in Reading Groups: An Online Survey of Face-to-Face and Virtual Book Clubs.' Convergence 9, no. 1 (2003): 66-90.

Shapin, S. (1994) A social History of Truth: Civility and Science in Seventeenth Century England. Chicago: University of Chicago Press, 1994.

Sims, J. (2007) Not enough understanding? Student experiences of diversity in UK universities, London: Runnymeade Trust.

Striphas, Ted. (2003) 'A Dilectic With the Everyday: Communication and Cultural Politics on Oprah Winfrey's Book Club.' Critical Studies in Media Communication 20, no. 3 (2003): 295-316.

Sullivan, A. and Brown, M. (2013) Social Inequalities in Cognitive Scores at age 16: The role of reading, Centre for Longitudinal Studies Working Paper 2013/10, London: Institute of Education. The Reading Agency and BOP Consulting (2015). 'Literature Review: the impact of reading for pleasure and empowerment.' Available at:

http://readingagency.org.uk/news/The\%20Impact\%20of\%20Reading\%20for\%20Pleasure\%20and\%2 OEmpowerment.pdf (Accessed $28^{\text {th }}$ January 2016).

Tienda, M. (2013) 'Diversity Inclusion: promoting integration in higher education', Educational Researcher, Vol. 42, 9: pp.467-475.

Tinto,V. (1975) 'Dropout from Higher Education: A Theoretical Synthesis of Recent Research' Review of Educational Research vol.45, pp.89-125.

Tinto, V. (1993) Leaving college: rethinking the causes and cures of student attrition. Chicago: Chicago University Press.

Twiton, A. (2007) Common reading programs in higher education. A Patricia Lindell Scholarship research project. https://gustavus.edu/library/Pubs/Lindell2007.html

Vasquez, J.M. (2005) 'Ethnic identity and Chicano literature: How ethnicity affects reading and reading affects ethnic consciousness.' Ethic and Racial Studies, 28(5), pp903-924.

Watts, J. and Brodin, L. (2011) 'Climbing over the fence: a history of self-publishing, in The Naked Author. London: Bloomsbury.

Wright, D. (2006) CRESC (ESRC Centre for Research on Socio-Cultural Change), School of Sociology, The Open University, UK. 'The Big Read: Cultural Authority and the Construction of the Popular Canon', International Conference of the Book, Boston, US.

\section{Websites and web links offering more information on shared reading programmes:}

https://gobigread.wisc.edu/

http://homepages.gac.edu/ fister/onebook.html

https://gustavus.edu/library/Pubs/Lindell2007.html

http://www.herts.ac.uk/connect/common-reading-programme

https://gobigread.wisc.edu/

http://homepages.gac.edu/ fister/onebook.html 
University of Hertfordshire, Shared Reading Project http://www.herts.ac.uk/connect/commonreading-programme 